\title{
Incidence of HIV among General Population Attending a Tertiary Care Hospital in Hyderabad, Telangana, India
}

\author{
R. Shyamala* and D. Achut Rao \\ Department of Microbiology, Malla Reddy Medical College for Women, Hyderabad, \\ Telangana, India \\ *Corresponding author
}

\section{A B S T R A C T}

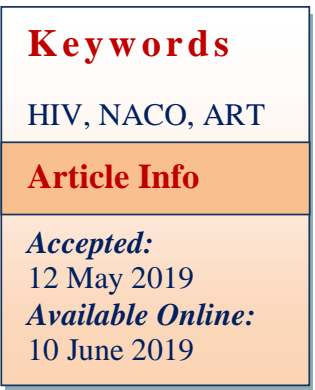

\section{Introduction}

In 1983 Lucomontegniere and colleagues from Pasteur Institute, Paris isolated a Retrovirus from a West African patient with persistent generalised lymphadenopathy which is a manifestation of AIDS. (Ananth Narayan). In India the first HIV case was detected in 1986, and since then it has been reported from all states and union territories. According to National Aids Control Organization (NACO) the national adult HIV prevalence in India is $0.36 \%$ (Harsha Kumar).

The first case of HIV was reported in India in 1986. Later in 1986, the Government of India established a national AIDS control committee under the ministry of Health and Family welfare to formulate a strategy for responding to HIV- Aids prevalence [UN AIDS]. HIV prevalence has been increasing among pregnant women in many regions with in the country, hence India launched a National AIDS Control Programme in 1987 [NACO Annual Report].

The National AIDS Control Programme (NACP) started in 1990 lays maximum emphasis on the widespread reach of information, education and communication on HIV/AIDS prevention (Laghave et al., 2015).

Six Indian states with high HIV and AIDS prevalence are Manipur (1.4\%), Andhra 
Pradesh (0.90\%), Mizoram (0.81\%), Nagaland $(0.78 \%)$, Karnataka $(0.63 \%)$ and Maharashtra $(0.55 \%)$. Prevalence of HIV infection among pregnant women in India is reducing. The prevalence of AIDS in India has declined in $2015(0.26 \%)$ as compared to 2001-2003 (0.38\%) (NACO, 2016).

In India women account for around one million out of 2.5 million estimated number of people living with HIV/AIDS. Their heightened vulnerability has both biological and socioeconomic reasons. Early marriage, violence and sexual abuse against women, illiteracy are the major socioeconomic reasons of their vulnerability to HIV infection. Their biological construct makes them more susceptible to HIV infection in any given heterosexual encounter. In 1992 India's National Aids Control Organisation was established by the ministry of Health and Family welfare with major support from World Bank.

Six Indian states are considered to have high HIV- AIDS prevalence (>1\%) Manipur, Nagaland, Andhra Pradesh, Tamil nadu, Karnataka and Maharashtra- as are 49 districts with in states.

Mizoram at $2.04 \%$ had the highest Adult HIV Prevalence in 2017, followed by Manipur at $1.43 \%$ and Nagaland at $1.15 \%$. Maharashtra accounted for $15 \%$ of the national total. It was followed by Andhra Pradesh, Karnataka, Telangana, Bengal, Tamil Nadu, UP and Bihar.

HIV prevalence has been increasing among pregnant women in many regions with in the country.

A single dose of $200 \mathrm{mg}$ of nevirapine will be administered to the mother during the first stage of labour and single dose of $2 \mathrm{mg} / \mathrm{kg}$ body weight to the newborn within 72 hours of birth is given, to prevent MTCT in developing countries (Pollard et al., 1998).

\section{Materials and Methods}

This is a retrospective study from Malla Reddy Medical College for Women and Hospital from January 2017 to December 2017. Blood samples were collected after pretest counselling and informed consent. The samples were tested for HIV antibodies as per NACO guidelines.

The first antibody test done was ELISA. If the initial result was positive, it was confirmed using two other supplemental tests. After HIV test results were known post-test counselling was done and the results were declared. Confidentiality of the data was maintained

\section{Results and Discussion}

5303 patients attending the hospital of Malla Reddy Medical College for Women, during the period of January 2017 to December 2017 were tested for HIV. Out of these 84 patients were tested positive accounting for $1.584 \%$. 44 were Male patients and 40 were Female patients.

Pie Diagram Showing the Incidence of HIV in a general population in a tertiary care hospital in Hyderabad.

In 1986, the first known case of HIV was diagnosed by Dr. Suniti Solomon, and her student, Dr. Selappan Nirmala amongst female sex workers in Chennai, Tamil Nadu (Sternberg et al., 2005; Pandey et al., 2016).

The average HIV prevalence among women attending antenatal clinic in India is $0.48 \%$ as per NACO annual report 2010-2011. The figures vary widely between the various states of India- Andaman and Nicobar Islands $0.25 \%$, Andhra Pradesh $1 \%$. 


\section{Incidence of HIV in a general population}

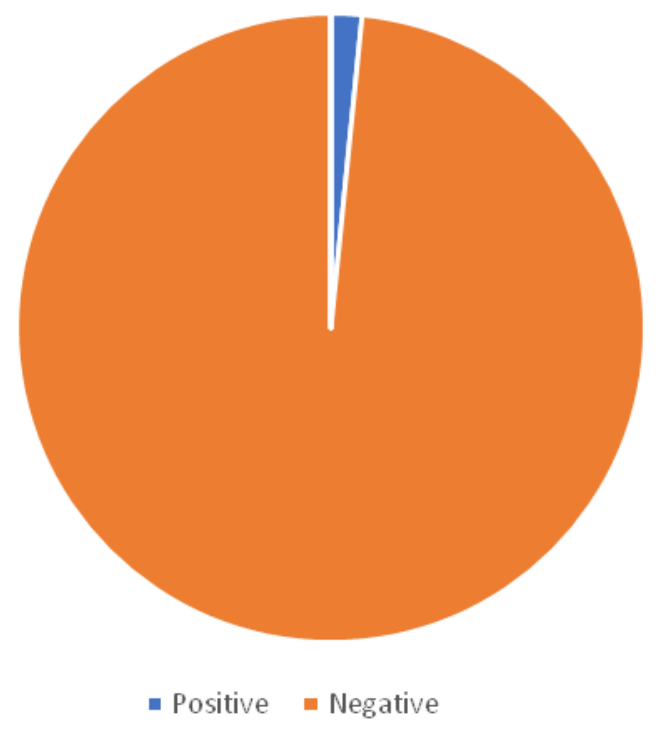

In Pune, India the HIV infection rate in antenatal women was $2.2 \%$ in 2002-2003 and has declined to $0.73 \%$ in 2006

Mother to child transmission is prevented by a four pronged strategy.

Primary prevention of HIV - By counselling the Antenatal women.

Prevent unintended pregnancies in the HIV positive women.

HIV positive and pregnant patient Prevention of Mother to child transmission.

HIV positive Mother \& Child - Care, support and treatment.

In India 90\% of the reported cases of HIV are aged between 15 and 40 years and belong to low socioeconomic groups [Monica Malta et $a l .$,$] .$

Mizoram at $2.04 \%$ had the highest Adult HIV Prevalence in 2017, followed by Manipur at $1.43 \%$ and Nagaland at $1.15 \%$. Maharashtra accounted for $15 \%$ of the national total. It was followed by Andhra Pradesh, Karnataka, Telangana, Bengal, Tamil Nadu, UP and Bihar.

In conclusion, mother to child transmission of HIV infection during pregnancy, delivery or breast feeding is responsible for more than 90\% of the HIV infection in children. Hence appropriate antenatal screening, interventions and preventive strategies during pregnancy, delivery and breastfeeding will bring down the mother to child transmission of HIV (Decock et al., 2000).

Programmes that provide services need to be implemented on public health services throughout the country, in order to decrease the vulnerability of the populations to HIV infection. The study of seroprevalence of HIV helps to formulate preventive steps in reducing the incidence of HIV infection. Developing many appropriate policies and educating people about HIV, promoting safe behaviour, counselling and creating more awareness among individuals in the community should be done. 


\section{References}

Ananthnarayan and Panicker's, a text book of Microbiology Universities Press 8th Edition pg-569.

Harsha Kumar. H.N., et al., Open Medicine 2009; 3(1): e 26-e30.

K. M. Decock, MG Fowler et al., JAMA 2000; 283(9): 1173-1180

Monica Malta et al., BMC Public Health,
2010, 10:317.

NACO Annual report 2002-2004

Pandey, Geeta 2016-08-30. "The woman who discovered India's first HIV cases". BBC News. Retrieved 2016-12-08.

R. B. Pollardetal. Clin Ther. 1998; 20; 107192

Sternberg, Steve 23 February 2005. HIV scars India USA Today.

\section{How to cite this article:}

Shyamala, R. and Achut Rao, D. 2019. Incidence of HIV among General Population Attending a Tertiary Care Hospital in Hyderabad, Telangana, India. Int.J.Curr.Microbiol.App.Sci. 8(06): 1352-1355. doi: https://doi.org/10.20546/ijcmas.2019.806.163 